Military Technical College Kobry El-Kobbah, Cairo, Egypt

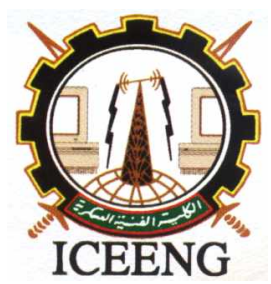

$6^{\text {th }}$ International Conference on Electrical Engineering ICEENG 2008

\title{
Design and Implementation of a Compact Microstrip Duplexer for 3G Mobile Communication Systems
}

$$
\text { By }
$$
M. Ali Soliman*
W. Swelam*
T. E. Taha**
S. Gazy***

\section{Abstract:}

In this paper, a microstrip duplexer for the third generation (3G) Universal Mobil Telecommunication System (UMTS) is investigated. Simple microstrip coupled-lines resonators have been used to develop the required structure. This satisfies different constraints such as a high electrical performance level (especially, a very narrow bandwidth, low insertion loss and a high out-of-band rejection), great compactness, low cost and a compatibility with a standard planar integration. Simulation and optimization processes are carried out with the aid of the Advanced Design System (ADS) electromagnetic simulator that uses the full-wave Method of Moment (MoM) numerical technique. Accurate results are obtained. The losses caused by both the substrate and metallization are taken into account during the simulation process. The duplexer is designed, simulated and implemented.

\section{Keywords:}

- Microstrip Duplexer, 3G Mobile Communication Systems, and UMTS.

* Egyptian Armed Forces.

** Faculty of Electronic Engineering, Menoufia University, Menouf, Egypt.

*** Benha Higher Institute of Technology (BHIT), Benha University, Benha, Egypt. 


\section{Introduction:}

Recently, more and more research work is focused on the development of small-scale, low-cost base stations for the third generation (3G) mobile communication systems throughout the world. By employing more sophisticated techniques, such as Code Division Multiple Access (CDMA), Spread Spectrum (SS), etc.., the 3G systems have obvious superiority to the $2 \mathrm{G}$ systems. System and circuit miniaturizing is one of the several approaches to bring down the system cost considerably. As such, the miniaturization technique suits for commercial system must allow for mass production with high tolerance and high reliability. For wireless communication systems, performances of a front-end in wireless transceivers must be complied to match the design specifications. For example, a high dynamic-range $3 \mathrm{G}$ transceiver can be accomplished either with low insertion loss RF filter, high-isolation duplexer, high gain and low noise-figure downconverter, or high linearity transmitter. With a single antenna, duplexer is normally used in RF transceivers to electrically isolate transmitter and receiver. To achieve high-dynamic range transceiver, a high-isolation and low insertion loss duplexer design is needed [1-5]. Duplexer can be realized in various media such as, microstrip [2-7], waveguide or Surface Acoustic Wave (SAW) [8]. Though planar microstrip is preferable due to its easy fabrication, low cost, small-size, low weigh, integrate-ability and compatibility with standard manufacturing process. Numerous techniques have been introduced to improve the microstrip duplexers' isolation performance but most of these techniques are yet improbable to apply in practice. For example, the stepped-impedance coupled-line resonator based hairpin filter [9] and the double-loop resonator [10] though considerably increase the isolation performance but the complexity in their design and implementations issues are of mainly practical concerns.

Therefore, this paper describes the complete design, simulation and fabrication of a microstrip duplexer. The design is simply based on twice coupled-line band-pass filters for both transmitter and receiver sections. 3-ports matching network is also designed to match between the two filters and an antenna. The proposed scheme allows size reduction, high isolation and enhances insertion loss considerably in passband. To validate the performance, the proposed scheme is designed for the UMTS communication systems at the center frequencies of $1.95 \mathrm{GHz}$ for downlink and $2.14 \mathrm{GHz}$ for uplink channels, while each operates at $60 \mathrm{MHz}$ bandwidth and with $130 \mathrm{MHz}$ bandwidth for separation. The design and complete schematic are shown in section 2. Simulation results' analysis and circuit board implementation are presented in section 3. Finally the conclusions are presented in section 4. 


\section{Design:}

It is known that a duplexer is usually composed of a transmitting filter, a receiving filter and a matching network. The receiving filter, which is used to reject out-band received signals, should be a band-pass filter such as the edge-coupled microstrip filter, coupledline microstrip filter or interdigital filter [1]. The transmitting filter, on the other hand, can be many kinds of filters such as band-pass filter, band-stop filter, low-pass filter, etc. [1]. For the implementation of a UMTS duplexer, two very narrow-band band-pass filters are designed. They are composed of twice, five-sections coupled-line microstrip filters for both transmitting and receiving parts. Matching network is designed to combine the two filters together so as to share one antenna. The matching network is also optimized to obtain sufficient isolation between the two filters. The complete structure is built over the Rogers Duroid 6010 microwave substrate with dielectric constant $\left(\varepsilon_{\mathrm{r}}=10.5\right)$, height $(\mathrm{h}=25 \mathrm{mil})$ and tangent loss $\left(\mathrm{t}_{\mathrm{g}}\right.$ loss $\left.=0.0023\right)$. Figure (1) Shows the structure layout with full dimensions, where each coupled-line section is defined by its line length (L), line thickness (T) and the gab between the coupled lines (G). The investigated microstrip duplexer is discriminative by its simple design and fabrication processes.

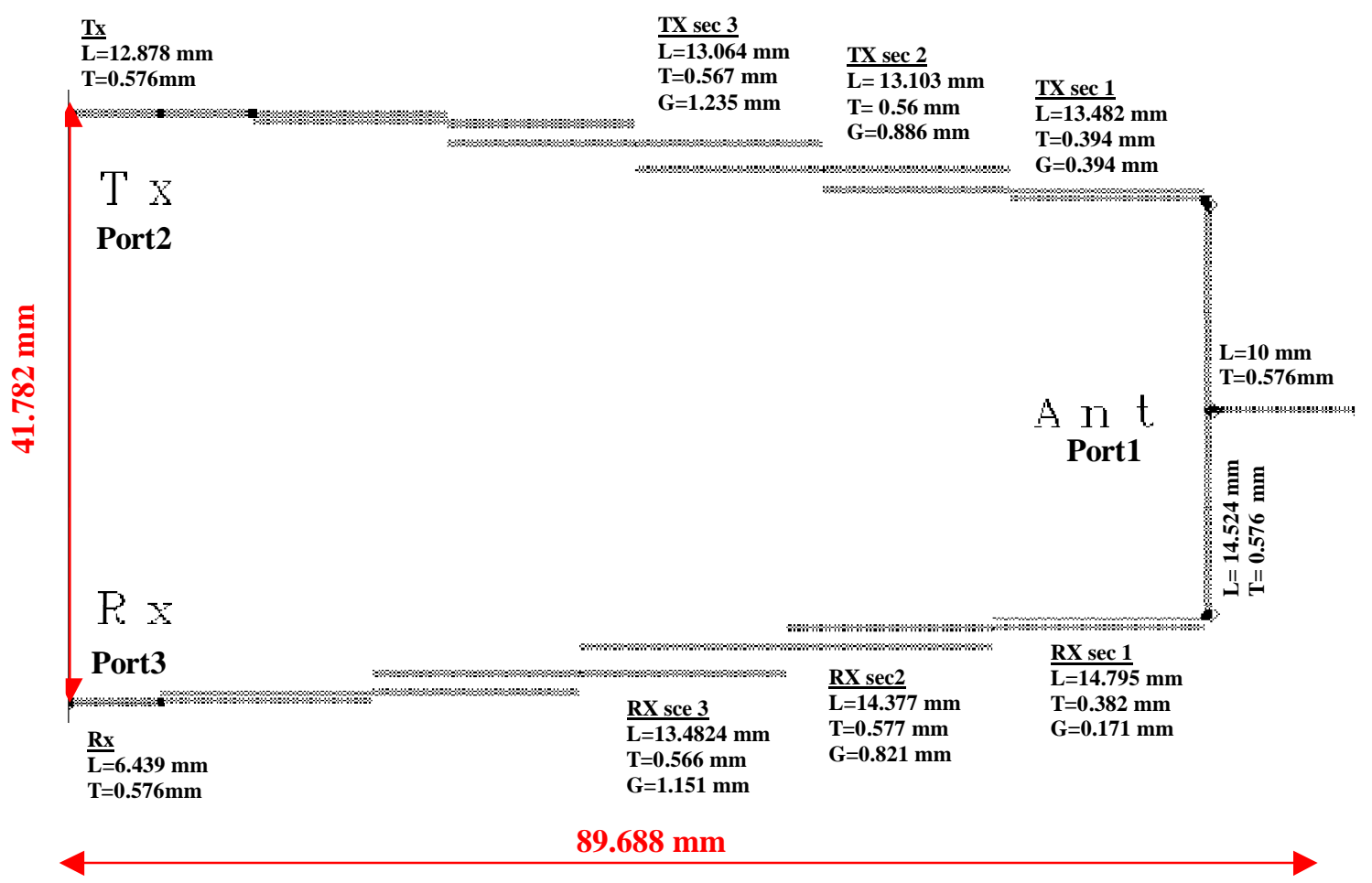

Figure (1): The complete structure layout with full dimensions. 


\section{Simulation, Analysis and Implementation:}

Method of Moment (MoM) technique using the Agilent Momentum Advanced Design System (MoM-ADS) full-wave simulator [11] is used during the simulation and optimization processes. The substrate dissipation factor $\left(\mathrm{t}_{\mathrm{g}} \mathrm{loss}=0.0023\right)$ and the microstrip line parameters (conductivity $=5.96 \mathrm{e}^{+7} \mathrm{~S} / \mathrm{m}$ and thickness $=17 \mu \mathrm{m}$ ) are considered during the simulation process. Figure (2) Shows that the pass-band of the transmitting filter is from $1.92 \mathrm{GHz}$ to $1.98 \mathrm{GHz}$ and for the receiving filter is from $2.11 \mathrm{GHz}$ to $2.17 \mathrm{GHz}$. The insertion loss of both filters is about $2.7 \mathrm{~dB}$ with good out of band rejection. Figure (3) Shows that the return loss at the antenna port $S_{11}$ is better than $-17 \mathrm{~dB}$ for both transmitting and receiving frequency bands. Figure (4) Shows that the return loss at both the transmitting port $S_{22}$ and the receiving port $S_{33}$ is better than $-18 \mathrm{~dB}$ within the frequency band of interest, this ensures good matching. Figure (5) Shows that the isolation between both the transmitting and receiving ports $S_{23}$ is better than $-20 \mathrm{~dB}$, which ensures good port isolation. Figure (6) Shows the implemented circuit board. The figure shows the board compactness in size with full dimensions of $89.688 \times 41.782 \mathrm{~mm}$.

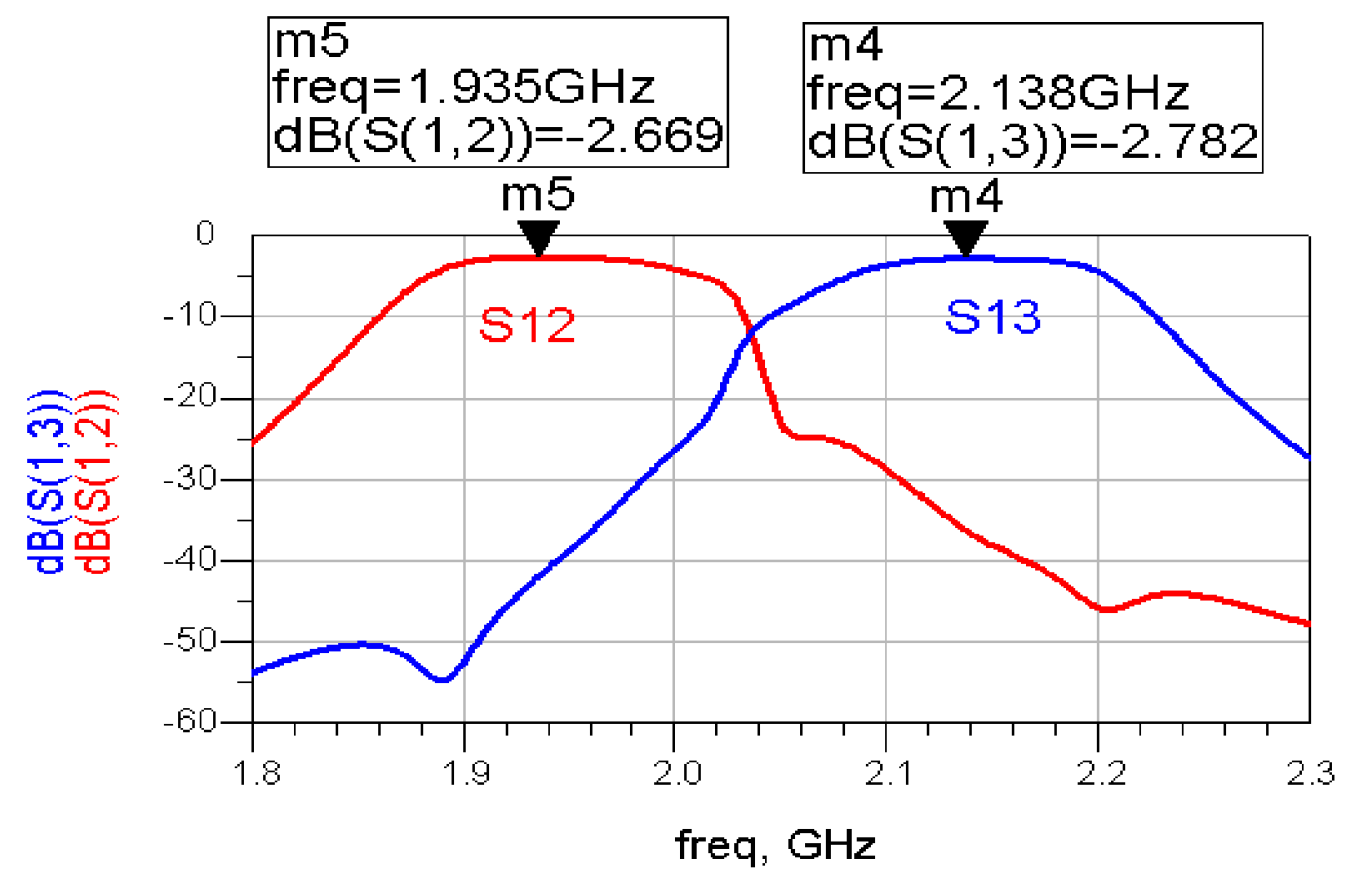

Figure (2): The insertion loss of both transmitting and receiving filters, $S_{12}$ and $S_{13}$ respectively. 
$\mathrm{m} 1$

freq=2.180G $\mathrm{Hz}$

$\mathrm{dB}(\mathrm{All} 3$ _mom. $S(1,1))=-22.359$

$m 6$

freq $=1.915 \mathrm{GHz}$

$\mathrm{dB}(\mathrm{All} 3$ _mom. $S(1,1))=-28.240$

S11

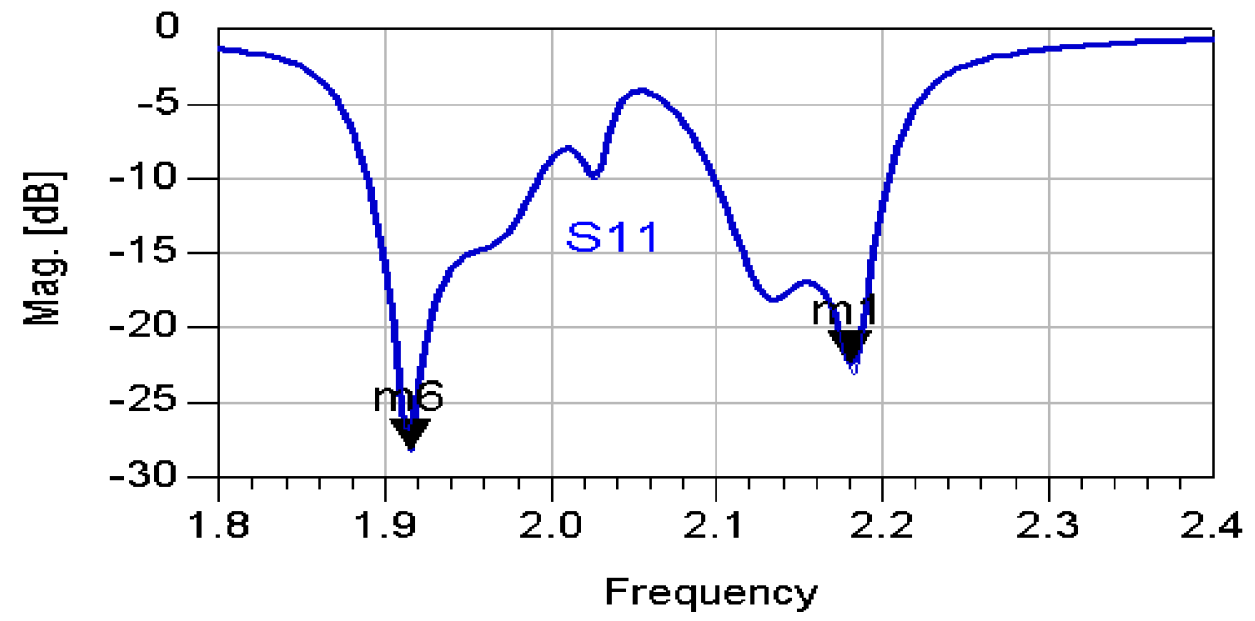

Figure (3): The return loss $S_{11}$ at the antenna port.

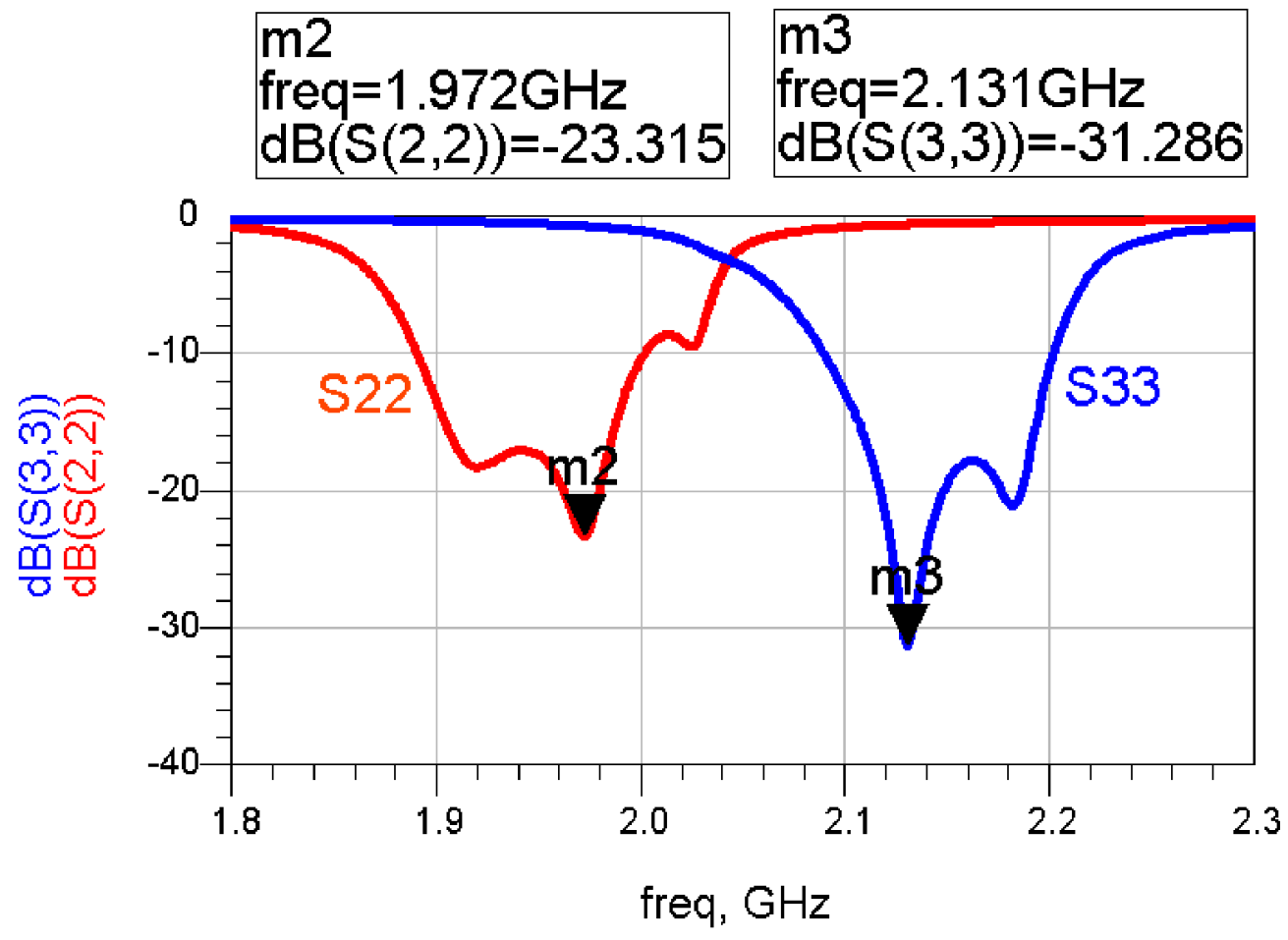

Figure (4): The return loss at both the transmitting port $S_{22}$ and the receiving port $S_{33}$. 


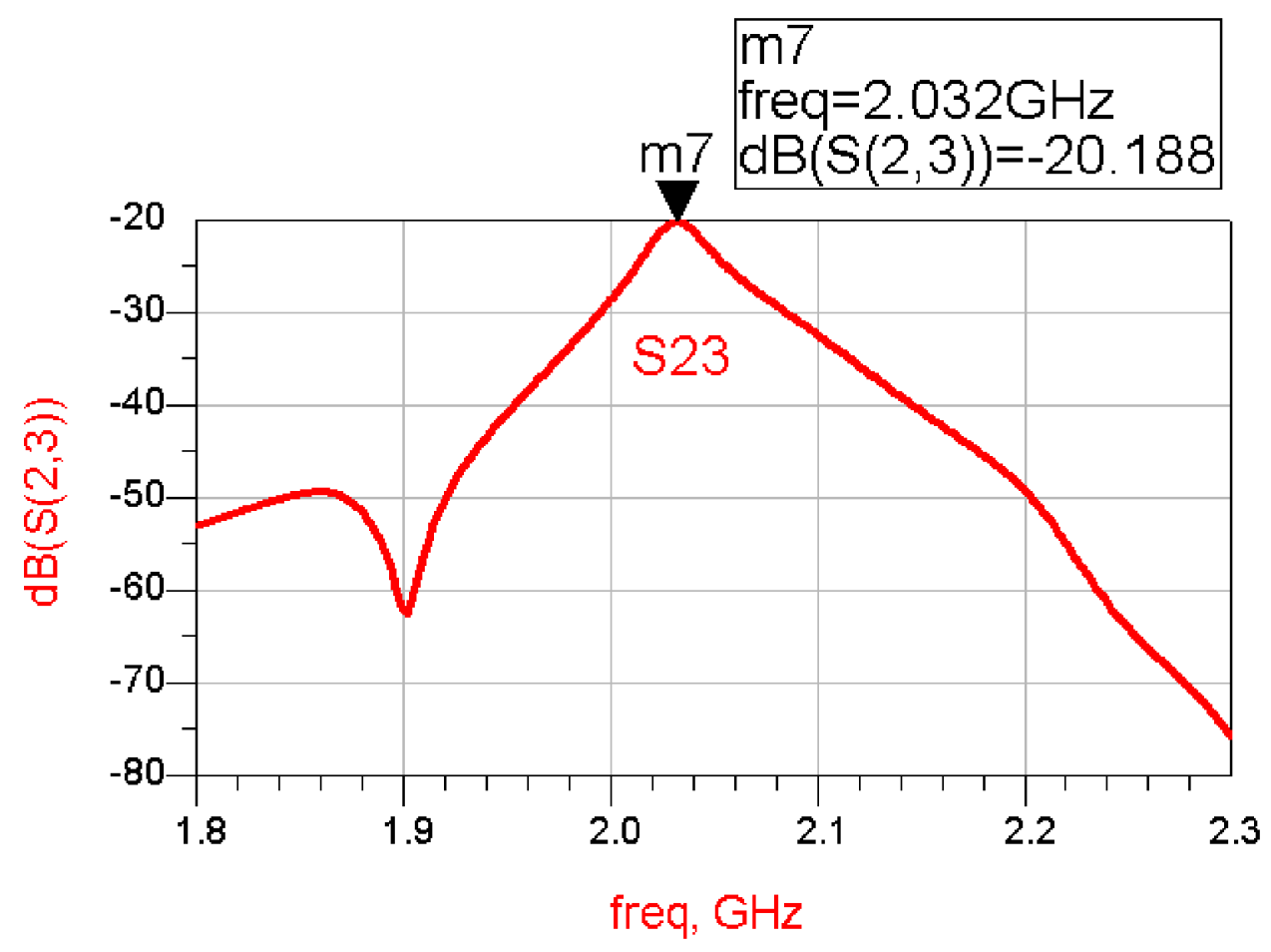

Figure (5): Isolation between both the transmitting and receiving ports $S_{23}$.

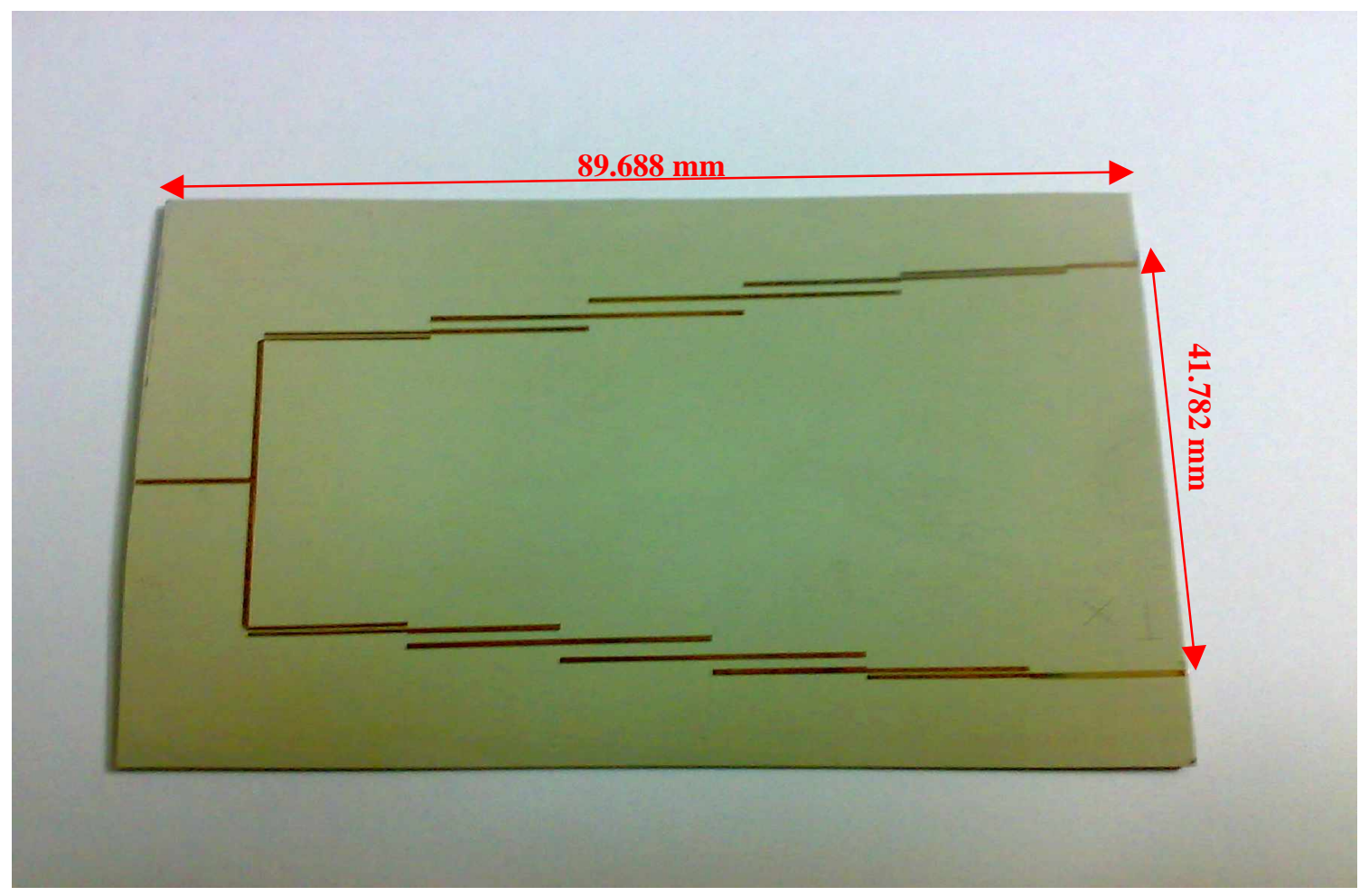

Figure (6): The implemented circuit board. 


\section{Conclusions:}

In this paper complete design simulation and implementation of a compact microstrip duplexer suitable for the future $3 \mathrm{G}$ mobile communication systems base stations is developed. The simulation results show high electrical performance in matching, isolation, insertion loss, and out of band rejection. The developed structure is suitable to work with planar microstrip antennas, planar antenna arrays and with the Microwave Monolithic Integrated Circuit (MMIC) different applications.

\section{References:}

[1] G. Matthaei, L. Young, and E. M. T. Jones, Microwave Filters, ImpedanceMatching Network and Coupling Structure, New York: McGraw-Hill, 1964.

[2] G. Matthaei and E. G. Cristal, "Multiplexer channel-separating units using interdigital and parallel-coupled filters," IEEE Trans. Microw.Theory Tech., vol. MTT-13, pp. 328-334, May, 1965.

[3] L. J. Ricardi, "A diplexer using hybrid junctions," IEEE Trans. Microw. Theory Tech., vol. MTT-14, no. 8, pp. 364-371, May, 1966.

[4] R. J. Wendel, "Printed-circuit complementary filters for narrow bandwidth multiplexers," IEEE Trans. Microw. Theory Tech., vol. MTT-16, pp. 147-157, March, 1968.

[5] M. H. Capstrick, "Microstrip lowpass-bandpass diplexer topology," Electron Lett., vol. 35, no. 22, pp. 1958-1960, October, 1999.

[6] J. Zhou and W. Hong, "Design of compact microstrip duplexers for 3G mobile communication system," in IEEE Int. Antenna and Propagation Symps. Dig., pp. 816-819, July, 2000.

[7] B. Strassner and K. Chang, "Wide-band low-loss high-isolation microstrip periodicstub diplexer for multiple-frequency applications," IEEE Trans. Microw. Theory Tech., vol. 49, no. 10, pp. 1818-1820, October, 2001.

[8] Jun Tsutsumi, et al. "A Miniaturized 3 x 3-mm SAW Antenna Duplexer," IEEE International Ultrasonics, Ferroelectrics, and Frequency Control Joint $50^{\text {th }}$ Anniversary Conference, 2004, pp. 945-958.

[9] S. Srisathit, S. Patisang, R. Phromloungsri, S. Bunnjaweht, S. Kosulvit, and M. Chongcheawchamnan, "High isolation and compact size microstrip hairpin diplexer," IEEE Microwave and Wireless Lett., vol. 15, no. 2, pp. 101-103, February, 2005.

[10] W. Jobjanprai, S. Chaimool, V. Viveck, and P. Akkraeakthalin, "A compact microstrip hairpin diplexer for IMT-2000 band," The 2nd ECTI International Conference (ECTI-CON2005), vol. 1, no. 2, pp. 726-729, 12-13 May, 2005.

[11] Advanced Design System, 2002 Momentum Software Manual, Agilent Technologies, CA: Palo Alto, Feb. 2002. 


\section{Nomenclatures:}

$\varepsilon_{\mathrm{r}} \ldots \quad$ Microwave substrate dielectric constant.

$\mathrm{t}_{\mathrm{g}}$ loss ... Microwave substrate tangent loss.

h ... Microwave substrate height [mil].

L ... The length of the coupled line section [mm].

$\mathrm{T} \ldots \quad$ The thickness of the coupled line single line [mm].

G ... The gap between the coupled lines [mm]. 